\title{
Morphological Variation Among Wild Populations of Chinese Rare Minnow (Gobiocypris rarus): Deciphering the Role of Evolutionary Processes
}

Author(s): Yongfeng He, Rui Li Jianwei Wang, Simon Blanchet and Sovan Lek

Source: Zoological Science, 30(6):475-483. 2013.

Published By: Zoological Society of Japan

DOI: http://dx.doi.org/10.2108/zsj.30.475

URL: http://www.bioone.org/doi/full/10.2108/zsj.30.475

BioOne (www.bioone.org) is a nonprofit, online aggregation of core research in the biological, ecological, and environmental sciences. BioOne provides a sustainable online platform for over 170 journals and books published by nonprofit societies, associations, museums, institutions, and presses.

Your use of this PDF, the BioOne Web site, and all posted and associated content indicates your acceptance of BioOne's Terms of Use, available at www.bioone.org/page/terms_of_use.

Usage of BioOne content is strictly limited to personal, educational, and non-commercial use. Commercial inquiries or rights and permissions requests should be directed to the individual publisher as copyright holder. 


\title{
Morphological Variation Among Wild Populations of Chinese Rare Minnow (Gobiocypris rarus): Deciphering the Role of Evolutionary Processes
}

\author{
Yongfeng $\mathrm{He}^{1,2}$, Rui $\mathrm{Li}^{1}$, Jianwei Wang ${ }^{1 *}$, Simon Blanchet ${ }^{3}$, and Sovan Lek \\ ${ }^{1}$ Institute of Hydrobiology, Chinese Academy of Sciences, Wuhan, Hubei 430072, China \\ ${ }^{2}$ Yangtze River Fisheries Research Institute, Chinese Academy of Fishery Sciences, \\ Wuhan, Hubei 430223, China \\ ${ }^{3}$ Université Paul Sabatier, Lab. Evolution and Diversité Biologique, UMR 5174, \\ CNRS - 118, route de Narbonne - 31062 Toulouse, Cedex, France
}

\begin{abstract}
Gobiocypris rarus Ye et Fu (1983) is an endemic cyprinid fish in China, and is considered to be an endangered species. From a conservation perspective, its population structure is interesting. In the present study, morphological variation, including morphometric and meristic traits, was assessed among wild samples collected in the upper Yangtze River basin. There were no significant meristic differences between sexes or among populations, except for scales in lateral line (LS). However, there were significant morphometric differences not only between sexes but also among populations. In discriminant function analysis, the first four discriminant functions explained $75.5 \%$ and $78 \%$ of the among-population morphometric variation for males and females, respectively. Almost all the truss network morphometric traits significantly contributed to population discrimination. By using all of the truss network morphometric traits, overall random assignments of male and female individuals into their original population were both $73.5 \%$. In addition, the degree of differentiation in phenotypic traits $\left(P_{\mathrm{ST}}\right)$ significantly exceeds that in neutral molecular markers $\left(F_{\mathrm{ST}}\right)$. However, no significant correlation between $P_{\mathrm{ST}}$ and $F_{\mathrm{ST}}$ was found in males or females. Overall, these results suggest that two evolutionary processes, including phenotypic plasticity and natural selection, may contribute to the morphological patterns observed in G. rarus.
\end{abstract}

Key words: Gobiocypris rarus, morphological variation, morphometrics, sexual dimorphism, population differentiation

\section{INTRODUCTION}

Studies of the population structure of threatened fishes are of theoretical interest for evolutionary biologists and of practical value for environmental managers. Quantitative variations of morphological and genetic traits have been extensively used to describe the population structure in many organisms (Murta, 2000; Silva, 2003; Turan et al., 2006; Clabaut et al., 2007), and have been of great concern for improving the conservation of imperiled species (Frankham et al., 2002).

In wild populations, adaptation to a local environment is often revealed by the analysis of morphological traits (Langerhans et al., 2003; Langerhans et al., 2007; Aguirre et al., 2008; Páez et al., 2008; Kristjánsson et al., 2011). Variation in morphological traits may result from three main evolutionary processes: genetic drift, natural selection, and/ or phenotypic plasticity. The latter case refers to cases in which a genotype adapts plastically to its environment, mainly through ontogenetic changes (Roff, 1992; Gianoli

\footnotetext{
* Corresponding author. Tel. : :+86-27-68780033;

Fax : +86-27-68780065;

E-mail: wangjw@ihb.ac.cn
}

and Valladares, 2012). Whether patterns of morphological adaptation are due to phenotypic plasticity or natural selection, both imply a strong role for the environment (either biotic or abiotic). However, the consequences for the evolutionary and ecological dynamics of populations are not the same, as in one case (natural selection) variation is transmitted to the next generation, whereas in the other case (phenotypic plasticity) variation is generally not transmitted (however, phenotypic plasticity can sometimes be transmitted, for instance through epigenetic or habitat inheritance, Agrawal, 2001; Pigliucci, 2005; Danchin et al., 2011). In contrast, genetic drift does not imply environmental effects, but rather indicates that effective population size is an important parameter to consider for predicting the evolutionary dynamics of populations. Deciphering between these evolutionary processes is a difficult but important task for setting appropriate conservation plans. This is particularly challenging in aquatic ecosystems, such as streams or rivers, because these ecosystems exhibit great spatial or temporal variability in both abiotic and biotic habitat parameters (Lowe-McConnell, 1987; Langerhans et al., 2007; Aguirre, 2009; Elmer et al., 2010; Collin and Fumagalli, 2011), and because gene flow and movements are constrained not only by river basin boundaries, but also by the upstream-downstream flows that often lead to asymmetric gene flow, hence dampening local 
adaptation in downstream sites (Kawecki and Holt, 2002; Morrissey and Kerckhove, 2009; Stelkens et al., 2012).

Sexual dimorphism is also a frequent source of morphological variation among populations (Kitano et al., 2007; Williams and Carroll, 2009). Differentiation in external structures between males and females are usually not directly related to reproduction. These sexually dimorphic traits in external morphology can result from both sexual and natural selection (Andersson, 1994; Oliveira and Almada, 1995; Kitano et al., 2007). Knowledge of sexual dimorphism is indispensable in the study of population structure on morphological traits, notably because a biased sex ratio can lead to spatial patterns for which processes can be incorrectly inferred if sexual dimorphism is not accounted for (Oliveira and Almada, 1995; Skjæraasen et al., 2006; Kitano et al., 2007; Aguirre et al., 2008).

The rare minnow, Gobiocypris rarus Ye et $\mathrm{Fu}$ (1983), is an endemic cyprinid fish in China (Ye and Fu, 1983; Chen, 1998). It is considered to be an endangered species due to its narrow distribution and small number of large remnant populations (Le and Chen, 1998; Wang et al., 1998; Li et al., 2004; Wang and Xie, 2004; Xiong et al., 2009). Its distribution is limited to the western part of Sichuan Province, China (Ding, 1994; Wang and Cao, 1997; Chen, 1998; Le and Chen, 1998). All known habitats of rare minnow are scattered, separated by dozens to hundreds of miles, indicating a discontinuous distribution for the species. Meanwhile, this fish has been used extensively as an aquatic laboratory animal in toxicology, fish pathology, developmental biology, and genetics (Wang, 1992, 1996, 1999; Wang et al., 1994; Wang and Cao, 1997; Jia et al., 2002; Zhong et al., 2005; Pei et al., 2008; Su et al., 2008). Very little is known about the adaptation of this species to environmental factors, which limits the setting of appropriate conservation plans (but see Shao et al., 2007; He et al., 2012).

The main goals of our study are to investigate intra- and inter-population morphological variation of $G$. rarus and to test for biological, ecological, and evolutionary processes driving morphological variation. To do so, we explored patterns of variation in morphometric and meristic characters of G. rarus in four sub-basins of the upper Yangtze River basin, and first tested whether this fish species displays sexual dimorphism in external morphology. We next compared the degree of phenotypic differentiation measured by the $P_{\mathrm{ST}}$ index, analogous to $Q_{\mathrm{ST}}$, but affected by environmental effects (Spitze, 1993; Raeymaekers et al., 2007; Brommer, 2011), against the neutral expectation set by allelic divergence in microsatellite markers $\left(F_{\mathrm{ST}}\right)$ to assess the relative roles of genetic drift, natural selection, and phenotypic plasticity for the observed population differentiations in body shape.

Several studies revealed that the accuracy of the approximation of $Q_{\mathrm{ST}}$ by $P_{\mathrm{ST}}$ is not dependent on the heritability of the trait, but rather depends on the extent to which variance across populations relative to variance within populations are determined by additive genetic effects (Brommer, 2011). It is well understood that nonadditive genetic variance or environmental factors and genotype-environment interactions may distort additive genetic variance when investigating only phenotypic variances (Pujol et al., 2008). When doing $P_{\mathrm{ST}} / F_{\mathrm{ST}}$ comparisons, it is usually assumed first that phenotypic variance equals additive genetic variance, excluding nonadditive genetic and environmental effects (Merilä, 1997). If $P_{\mathrm{ST}}$ is not significantly different from $F_{\mathrm{ST}}$, the divergence in quantitative traits is likely to be due to genetic drift. However, if $P_{\mathrm{ST}}$ is significantly different from $F_{\text {ST }}$ (either greater or smaller), selection or phenotypic plasticity are likely factors underlying divergence in quantitative traits (Merilä and Crnokrak, 2001).

\section{MATERIALS AND METHODS}

\section{Sample collection}

G. rarus were collected by nets in 2008 from nine sites, located in the Sichuan Province, China (Fig. 1, Table 1). These nine sites are from four river basins: the Tuojiang River, the Minjiang River, the Dadu River, and the Qingyi River. Following capture, fish were placed in water vats to keep them alive during transportation. They were then anesthetized by MS222 before they were weighed and measured. Finally, fish were dissected in order to determine the sex. Sample size in this study varied between 30 and 50 , whereas Reist (1985) recommended for morphological analysis the sample size of at least 25 specimens.

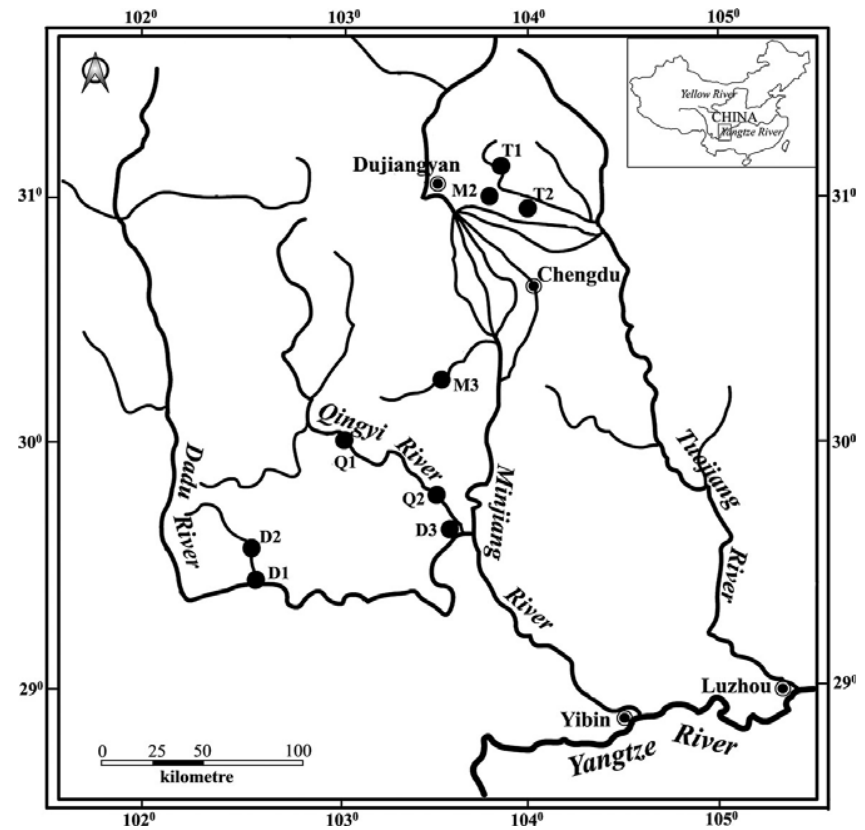

Fig. 1. Map of the sampling locations for Gobiocypris rarus.

Table 1. Sampling details of Gobiocypris rarus used in this study.

\begin{tabular}{|c|c|c|c|c|c|}
\hline Sampling sites & Abbr. & Location & $\begin{array}{l}\text { Sample } \\
\text { size }\end{array}$ & $\begin{array}{l}\text { Sex } \\
(M / F)\end{array}$ & MSL \\
\hline Haiwozi & T1 & Tuojiang River basin & 50 & $27 / 23$ & $44.40(6.36)$ \\
\hline Penzhou City & T2 & Tuojiang River basin & 50 & $17 / 33$ & $34.81(6.10)$ \\
\hline Lichun Town & M2 & Minjiang River basin & 30 & $18 / 12$ & $38.00(6.71)$ \\
\hline Qionglai City & M3 & Minjiang River basin & 50 & $17 / 33$ & $38.40(3.76)$ \\
\hline Yaan City & Q1 & Qingyi River basin & 50 & $23 / 27$ & $37.15(5.75)$ \\
\hline Jiajiang County & Q2 & Qingyi River basin & 50 & $40 / 10$ & $31.65(5.26)$ \\
\hline Liusha River mouth & D1 & Dadu River basin & 31 & $23 / 8$ & $37.17(6.35)$ \\
\hline Jiuxiang Town & D2 & Dadu River basin & 50 & $16 / 34$ & $34.21(4.56)$ \\
\hline Leshan City & D3 & Dadu River basin & 50 & $25 / 25$ & $41.50(4.68)$ \\
\hline
\end{tabular}

Abbr. = Abbreviation. MSL represents mean standard length $(\mathrm{mm})$ of each site. Standard deviations of MSL are given in parentheses. 


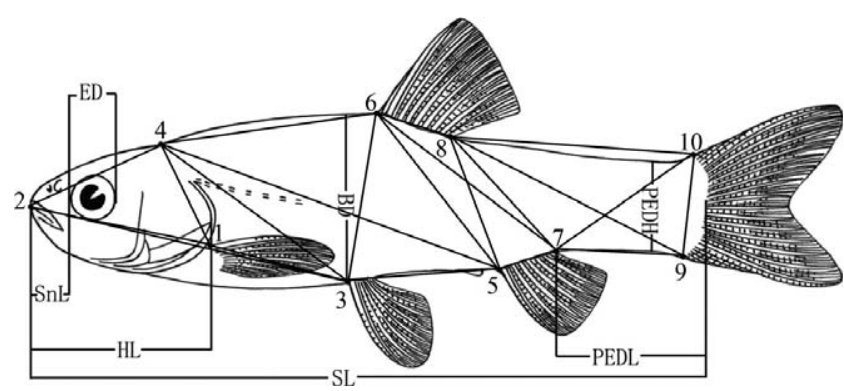

Fig. 2. Traditional morphometric measurements and truss network measurements based on 10 landmarks of Gobiocypris rarus are shown. The 10 landmarks represent: 1, pectoral fin insertion; 2, anteriormost tip of snout; 3 , pelvic fin insertion; 4, posterior point of the neurocranium; 5 , anal fin origin; 6 , dorsal fin origin; 7 , posterior end of anal fin base; 8 , posterior end of dorsal fin base; 9 , ventral origin of caudal fin; 10 , dorsal origin of caudal fin.

\section{Morphometrics}

All measurements were taken on the left side of fish by the same person in order to minimize measurement bias. Traditional measurements and the truss network system were used to describe the shape of fish body, based on the methods of Strauss and Bookstein (1982) and Bookstein et al. (1985). Traditional data, such as standard length (SL), body depth (BD), head length (HL), snout length $(\mathrm{SnL})$, eye diameter (ED), distance between eyes (DBE), peduncle length (PEDL), and peduncle height $(\mathrm{PEDH})$ were recorded, as shown in Fig. 2. In the truss network analysis, 10 landmarks determining 21 distances were produced and measured, as illustrated in Fig. 2. The truss data are expressed as D1-2, D2-4, D4-3, and so on. For example, D1-2 means the distance between landmarks 1 and 2. Images of thawed fish were acquired from a fixed distance with a high-resolution digital camera. DBE was manually measured by using a digital caliper with an accuracy of 0.01 $\mathrm{mm}$, and other measurements were analyzed using TpsDig 2.04 (Rohlf, 2005).

\section{Meristics}

Meristic characters were examined using the number of: pectoral fin rays (PFR), dorsal fin rays (DFR), ventral fin rays (VFR), anal fin rays (AFR), and scales in lateral line (LS) under a binocular stereomicroscope.

\section{Statistical analysis}

Morphometric and meristic characters were considered separately in statistical analyses, as these variables are different both statistically (the former are continuous while the later are discrete) and biologically (the latter are fixed early in development, while the former are more susceptible to the environment) (Ihssen et al., 1981).

Transformation of absolute measurements to size-independent shape variables was the first step of the analysis. In the present study, no significant correlations were observed between meristic characters and standard lengths of samples, indicating meristic characters were independent of fish size and the original meristic data were not transformed. Difference in meristic characters between male and female samples was revealed by non-parametric Kruskal-Wallis test. To identify any statistically significant differences in meristic characters among populations, non-parametric Kruskal-Wallis tests were also performed. After Kruskall-Wallis test, multiple comparison tests between populations were conducted using the 'pgirmess' package in the $\mathrm{R}$ software (Ihaka and Gentleman, 1996; Giraudoux, 2006).

Significant correlations were observed between morphometric characters and standard length of samples. In order to eliminate any variation resulting from allometric growth, all morphometric measurements were standardized according to Reist (1985). The formula is $M_{\text {adj }}=\log M-b\left(\log L_{o}-\log L_{s}\right)$, where $M_{\text {adj }}$ is the size adjusted measurement, $M$ the original morphometric measurement, $L_{s}$ the overall mean of standard length for all fish from all samples, and $L_{o}$ the standard length of fish. The parameter $b$ was estimated for each character from the observed data as the slope of the regression of $\log M$ on $\log L_{o}$, using all specimens. Correlation coefficients between transformed variables and standard length were calculated to check if the data transformation was effective in removing the effect of size in the data.

The homoscedasticity of morphometric data was firstly tested by using Bartlett's test (Snedecor and Cochran, 1989) and their normality by using Shapiro's test (Shapiro and Wilk, 1965). There were no severe departures from homoscedasticity and normality $(P>$ $0.05)$. Following size-correction, the differences in morphometric variables between male and female samples were determined using multivariate analysis of variance (MANOVA). If significant sex differences are identified, male and female samples should be analyzed separately. To verify if there were any statistically significant differences among populations, both MANOVA and analysis of variance (ANOVA) were performed. Afterwards, discriminant analysis (DA) was conducted to determine which morphometric variables best discriminate populations. Standardized coefficients for each variable in each discriminant function represent the contribution of the respective variable to the discrimination among populations. A random Monte Carlo test with 1000 permutations was used to test the significance of morphometric variables among populations. A holdout procedure (i.e., $2 / 3$ of the data as the training set and the remaining $1 / 3$ as the test set) was performed to test the ability of the model to discriminate between populations, so that the proportion of individuals correctly re-allocated was obtained. All these analyses were conducted using $\mathrm{R}$ software (Ihaka and Gentleman, 1996). In MANOVA and discriminant analysis, only truss network morphometric traits were used.

\section{Correlating morphology and genetics}

Pairwise genetic divergence at neutral markers was measured as $F_{\mathrm{ST}}$ values obtained from eight microsatellite markers (see He et al., 2012). The specimens used in microsatellite analyses were the same as those in the present study (Table 1). In order to correspond with the morphological analysis, we recalculated $F_{\text {ST }}$ values by separating female and male samples. The riparian geographical distance (RD) was calculated along the closest connected water system in Google Earth 5.0 (Google Inc., 2009).

A dimensionless measure of among-population phenotypic differentiation for quantitative traits, analogous to Wright's (1951) $F_{\mathrm{ST}}$, can be defined as $P \mathrm{ST}=c \sigma_{\mathrm{b}}{ }^{2} /\left(c \sigma_{\mathrm{b}}{ }^{2}+2 h^{2} \sigma_{\mathrm{w}}{ }^{2}\right)$ (Spitze, 1993; Storz, 2002; Raeymaekers et al., 2007; Brommer, 2011). In this formula, $\sigma_{b}{ }^{2}$ and $\sigma_{\mathrm{w}}{ }^{2}$ are the inter-population and intra-population variance components for a phenotypic trait in the wild, respectively; $h^{2}$ denotes the heritability (the proportion of phenotypic variance that is because of additive genetic effects); the scalar $c$ expresses the proportion of the total variance that is presumed to be because of additive genetic variance across populations. Due to the inability to estimate true $c$ and $h^{2}$ for a particular trait across wild populations, we assumed that $c=h^{2}$ in the present study. Similarly, female and male samples were separated before calculating $P_{\mathrm{ST}}$ values. The partitioning of phenotypic variance within and among populations of G. rarus was assessed using ANOVA. A intra-population variance $\left(\sigma_{\mathrm{w}}{ }^{2}\right)$ was estimated by equating observed intra-population mean squares $\left(M S_{\text {within }}\right)$ to their expectations. The added variance component attributable to differences among populations $\left(\sigma_{b}{ }^{2}\right)$ was estimated as $\sigma_{b}{ }^{2}=\left(M S_{\text {between }}-M S_{\text {within }}\right) / n_{0}$, where $M S_{\text {between }}$ is an unbiased estimate of the between-population variance and $n_{0}$ is the average sample size (Sokal and Rohlf, 1995). For each comparison, the average sample size $n_{0}$ was calculated as $n_{0}=1 /(\alpha-1)^{\star}$ 
( $\left.\sum^{\alpha} n_{i}-\sum^{\alpha} n_{i}^{2} / \sum^{\alpha} n_{i}\right)$, where $\alpha$ equals the number of populations compared and $n$ equals to the number of individuals in the ith population sample. Cls for $P_{\text {ST }}$ were estimated by 1000 bootstrap replicates. $P_{\text {ST }}$ at each trait was estimated between all population pairs. These analyses were conducted using the $\mathrm{R}$ software.

To test whether levels of phenotypic divergence, genetic divergence, and riparian geographic distance were correlated, we calculated the correlations between pairwise $P_{\mathrm{ST}}, F_{\mathrm{ST}}$ and riparian geographic distance with Mantel tests (Mantel, 1967). Partial Mantel tests were used to test correlations between pairwise $P_{\text {ST }}$ and $F_{\text {ST }}$ after controlling for riparian geographic distance. These analyses were conducted using the library vegan in the R software. In order to compare the level of phenotypic divergence with neutral genetic divergence, pairwise $P_{\mathrm{ST}}$ values were compared with pairwise $F_{\mathrm{ST}}$ values using Wilcoxon signed-rank test in STATISTICA 6.0 (StatSoft, 2001).

\section{RESULTS}

\section{Meristics}

No significant sex dimorphism was revealed in meristic characters $(P>0.05)$. The non-parametric Kruskal-Wallis tests also showed no significant differences among populations for almost all meristic characters $(P>0.05)$ except for scales in lateral line (LS). The multiple comparison tests revealed significant LS differences only between some population pairs $(P<0.05$, Fig. 3). Overall, the ranges of all meristic counts widely overlapped, and the modes of meristic characters were equal or close to each other among populations of $G$. rarus.

\section{Morphometrics}

After size-adjustment calculations, no significant correlation coefficients between transformed variables and standard length were found, indicating that the size effect had been successfully removed with the allometric transformation. Therefore, none of the variables was discarded from the following analyses.

Overall, there were significant differences between

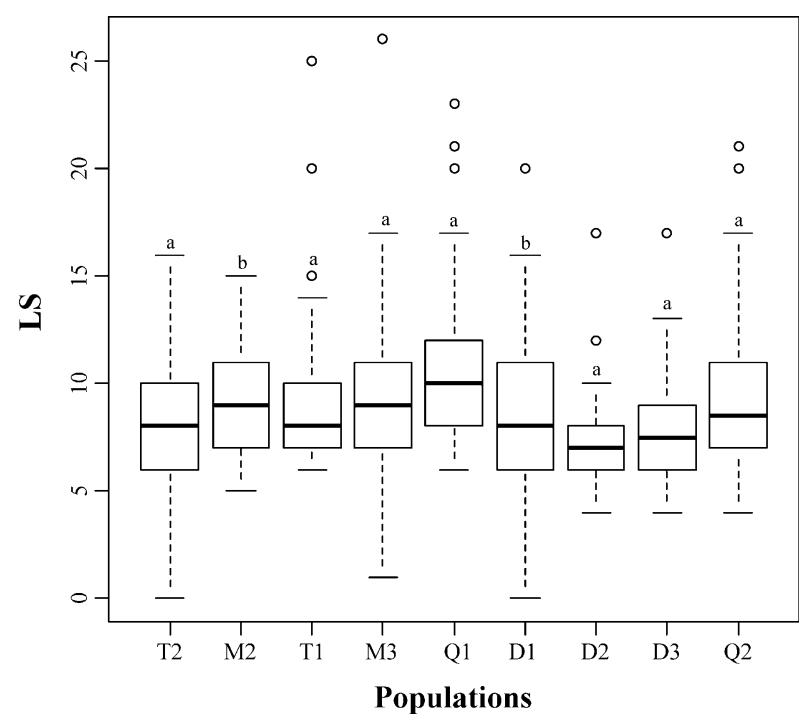

Fig. 3. The box-plot of a significant meristic character LS (scales in lateral line) of Gobiocypris rarus in each population: median, 25$75 \%$, maximum, minimum, outlier. Different characters $(\mathrm{a} / \mathrm{b})$ marked in the figure represent significant differences, while the same character means non-significant difference. males and females when twenty-one truss network morphometric variables were considered in a single analysis (MANOVA, $P<0.001)$. ANOVA revealed that eighteen morphometric traits (BD, DBE, PEDL, PEDH, D1_2, D4_3, D3_1, D2_3, D4_6, D5_3, D3_6, D4_5, D6_8, D7_5, D10_9, D9_7, D7_10, and D8_9) showed significant differences between sexes $(P<0.05)$. Therefore, male and female samples were separately analyzed in further analyses.

For both female and male samples, MANOVA showed that morphological differences among populations were significant for all truss network morphometric measurements $(P<0.001)$. ANOVA showed that most of all the morphometric traits in females were significantly different among populations, with the same result for males (Table 2).

In discriminant function analysis, eight discriminant functions (DFs) were generated, and the random Monte Carlo permutation test showed that all studied populations were significantly discriminated not only in females but also in males $(P<0.001)$. The first four functions of the discriminant analysis explained $78.0 \%$ of variance in all the truss network morphometric traits of $G$. rarus female samples, while explaining $75.5 \%$ of variance for male samples. Most of truss network morphometric traits in females (17 traits) or males (16 traits) had high allometric shape contributions to the first four discriminant functions. The truss network morphometric traits of females and males contributing to the first two discriminant functions are shown in Fig. 4 and Fig. 5, respectively.

After separating male and female samples, the overall random assignment of individuals into their original popula-

Table 2. Results ( $F$ value and $P$ value) from ANOVA, degree of phenotypic divergence in quantitative traits among populations $\left(P_{\mathrm{ST}}\right)$ for each size-corrected morphometric character.

\begin{tabular}{lrrrrrr}
\hline \multirow{2}{*}{ Variables } & \multicolumn{3}{c}{ Female } & & \multicolumn{3}{c}{ Male } \\
\cline { 2 - 7 } & $F$ value & $P$ value & $P_{\text {ST }}$ & $F$ value & $P$ value & \multicolumn{1}{c}{$P_{\text {ST }}$} \\
\hline HL & 133.610 & $<0.001$ & 0.749 & 82.642 & $<0.001$ & 0.644 \\
DBE & 116.320 & $<0.001$ & 0.721 & 31.646 & $<0.001$ & 0.404 \\
D1_2 & 57.439 & $<0.001$ & 0.559 & 1.713 & 0.192 & 0.016 \\
D1_4 & 57.253 & $<0.001$ & 0.558 & 3.217 & 0.074 & 0.047 \\
D7_10 & 37.079 & $<0.001$ & 0.448 & 63.560 & $<0.001$ & 0.580 \\
SnL & 29.776 & $<0.001$ & 0.393 & 45.972 & $<0.001$ & 0.499 \\
ED & 26.943 & $<0.001$ & 0.368 & 18.297 & $<0.001$ & 0.277 \\
D3_1 & 25.266 & $<0.001$ & 0.353 & 17.179 & $<0.001$ & 0.263 \\
PEDL & 22.487 & $<0.001$ & 0.326 & 23.544 & $<0.001$ & 0.333 \\
D10_9 & 20.768 & $<0.001$ & 0.308 & 26.142 & $<0.001$ & 0.357 \\
D9_7 & 18.137 & $<0.001$ & 0.278 & 25.786 & $<0.001$ & 0.354 \\
D6_8 & 16.087 & $<0.001$ & 0.253 & 6.361 & 0.012 & 0.106 \\
D2_4 & 14.015 & $<0.001$ & 0.226 & 3.126 & 0.079 & 0.045 \\
D8_10 & 6.431 & 0.012 & 0.109 & 19.740 & $<0.001$ & 0.293 \\
D8_9 & 4.430 & 0.037 & 0.072 & 11.422 & $<0.001$ & 0.187 \\
D5_3 & 3.979 & 0.047 & 0.063 & 22.543 & $<0.001$ & 0.323 \\
D6_5 & 3.659 & 0.057 & 0.056 & 2.493 & 0.116 & 0.032 \\
D3_6 & 3.092 & 0.080 & 0.045 & 6.297 & 0.013 & 0.105 \\
PEDH & 1.670 & 0.198 & 0.015 & 0.719 & 0.398 & -0.006 \\
D6_7 & 1.323 & 0.251 & 0.007 & 0.162 & 0.688 & -0.019 \\
D4_5 & 1.194 & 0.276 & 0.004 & 3.000 & 0.085 & 0.042 \\
D4_6 & 0.838 & 0.361 & -0.004 & 6.976 & 0.009 & 0.117 \\
D8_7 & 0.767 & 0.382 & -0.005 & 0.886 & 0.348 & -0.003 \\
D7_5 & 0.504 & 0.479 & -0.011 & 3.033 & 0.083 & 0.043 \\
D4_3 & 0.378 & 0.539 & -0.014 & 3.322 & 0.070 & 0.049 \\
D2_3 & 0.253 & 0.616 & -0.017 & 7.615 & 0.006 & 0.128 \\
D5_8 & 0.244 & 0.622 & -0.017 & 0.520 & 0.472 & -0.011 \\
BD & 0.020 & 0.887 & -0.023 & 1.137 & 0.288 & 0.003 \\
\hline & & & & & &
\end{tabular}



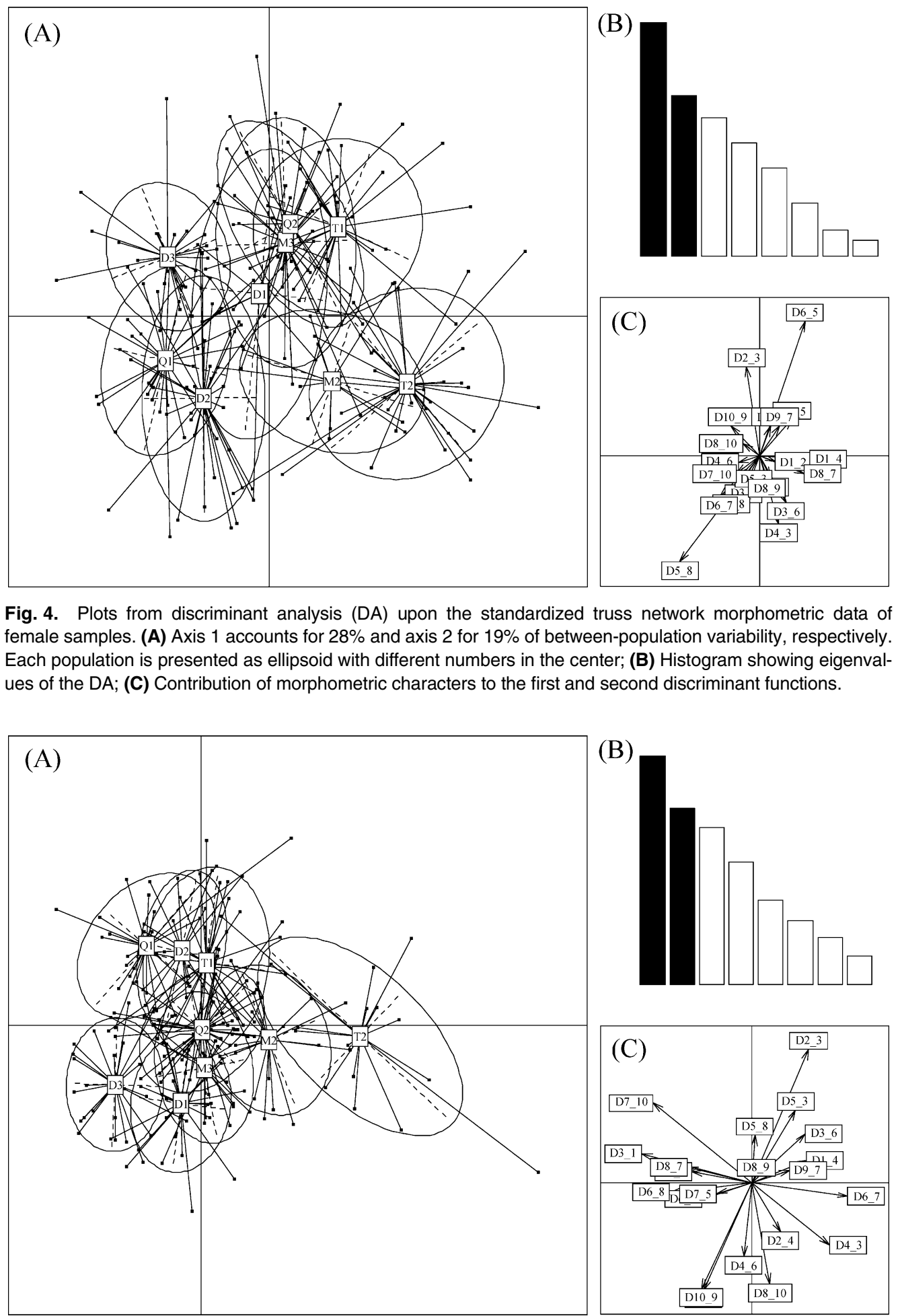

$100 \%$ of the Q2 female individuals were correctly classified to their original group. For male samples, almost all the populations had high correct classification (> 62.5\%), except for population M3 (only 50\%). The highest correct classification was found in population T2 (100\%).

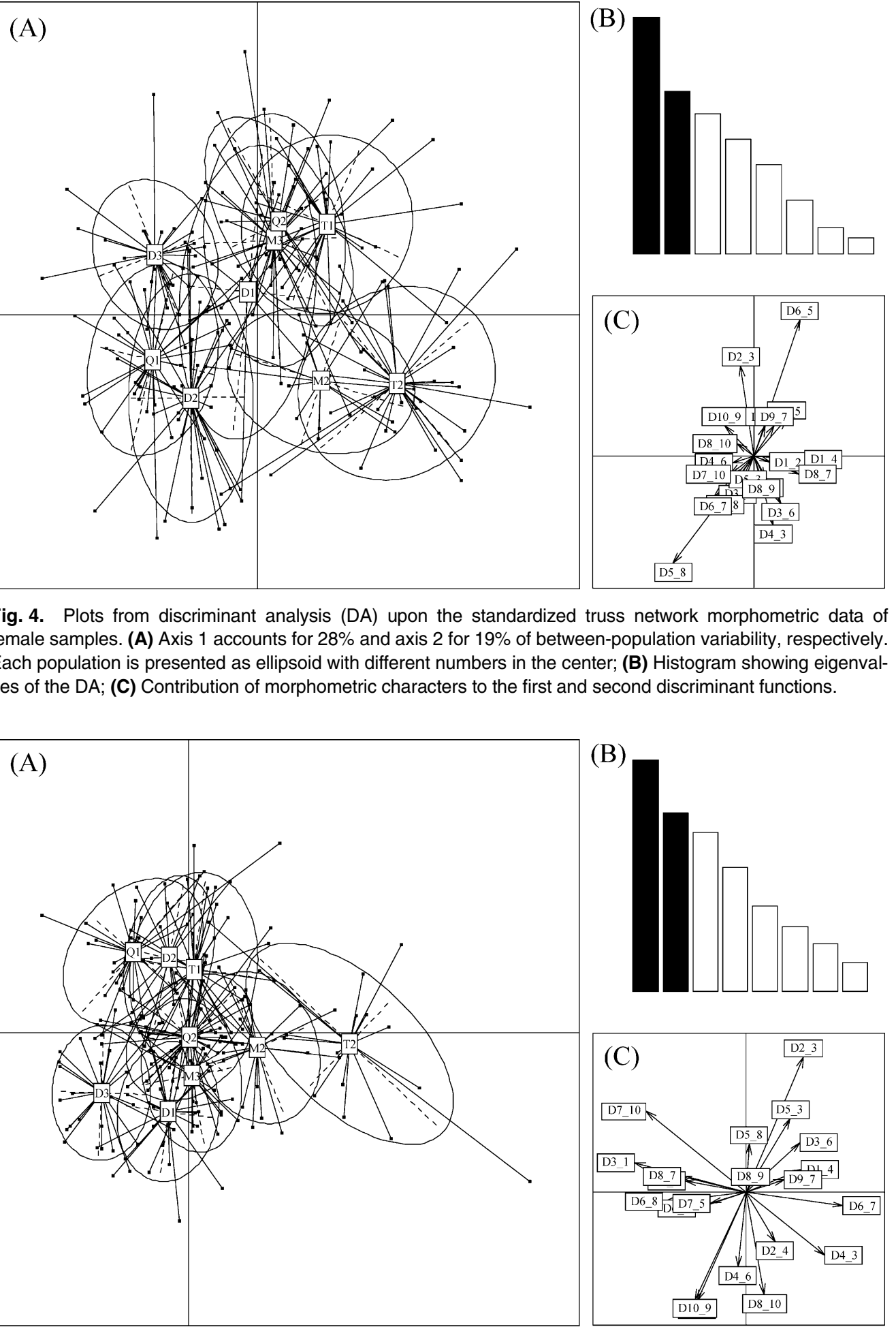

Fig. 4. Plots from discriminant analysis (DA) upon the standardized truss network morphometric data of female samples. (A) Axis 1 accounts for $28 \%$ and axis 2 for $19 \%$ of between-population variability, respectively. Each population is presented as ellipsoid with different numbers in the center; (B) Histogram showing eigenvalues of the DA; (C) Contribution of morphometric characters to the first and second discriminant functions.
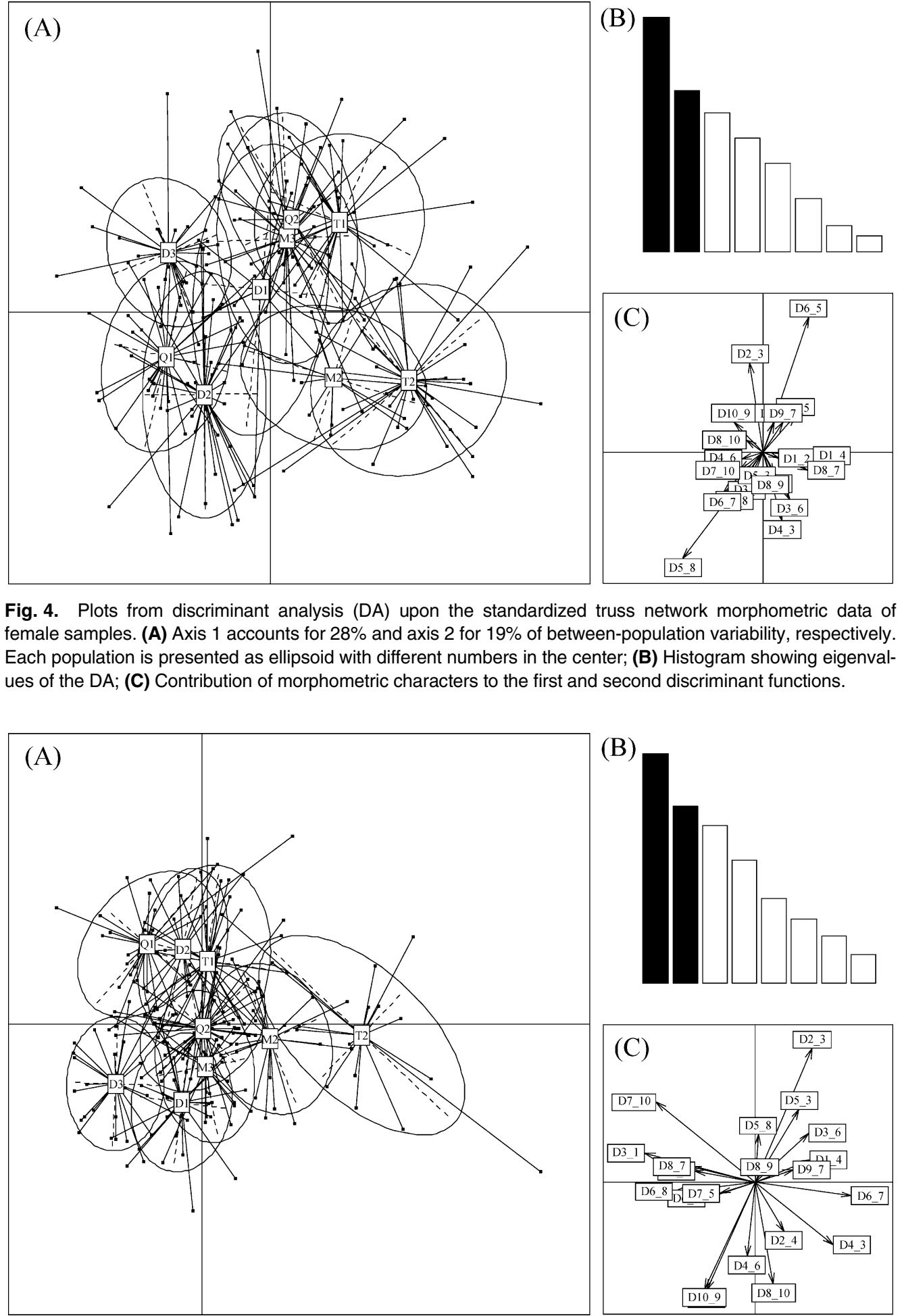

Fig. 5. Plots from discriminant analysis (DA) upon the standardized truss network morphometric data of male samples. (A) Axis 1 accounts for $25 \%$ and axis 2 for $19 \%$ of between-population variability, respectively. Each population is presented as ellipsoid with different numbers in the center; (B) Histogram showing eigenvalues of the DA; (C) Contribution of morphometric characters to the first and second discriminant functions.

tions were $73.5 \%$ for both females and males by hold-out procedure (Table 3 and Table 4). For female samples, most populations had relatively high correct classification (> 62.5\%), except for population M2 (only 33.3\%) and D1 (0\%). Indeed, tions between $P_{\mathrm{ST}}$ for single morphometric trait and $F_{\mathrm{ST}}$ for all neutral microsatellite loci were found $(P>0.05)$. Similarly, there were also no significant correlations between $P_{\mathrm{ST}}$ for most of single morphometric traits and $F_{\mathrm{ST}}$ for all neutral

Comparison of genetic and morphological divergence

For females, phenotypic divergence $\left(P_{\mathrm{ST}}\right)$ among populations for each morphometric trait varied from $-0.023(\mathrm{BD})$ to $0.749(\mathrm{HL})$, with a mean value of 0.208 (Table 2). For males, phenotypic divergence $\left(P_{\mathrm{ST}}\right)$ among populations for each morphometric trait varied from -0.019 (D6_7) to 0.644 $(\mathrm{HL})$, with a mean value of 0.186 (Table 2). Pairwise mean $P_{\mathrm{ST}}$ comparison of populations for all morphometric traits varied from 0.026 (between populations M2 and T2) to 0.267 (between populations T1 and D2) for females, and from 0.006 (between populations M3 and D1) to 0.196 (between populations Q2 and T2) for males (Table 5).

For both female and male samples, Mantel tests revealed no significant correlations between mean $P_{\mathrm{ST}}$ and mean $F_{\mathrm{ST}}$, irrespective of whether riparian geographic distance was considered as a controlled factor (Table 6). Pairwise Mantel tests also showed that no significant correlations between mean $P_{\mathrm{ST}}$ and riparian geographic distance for both female and male samples (Table 6). For male samples, no significant correla- 
Table 3. Proportion of female individuals classified correctly into their original population over 21 truss network morphometric characters using hold-out procedure.

\begin{tabular}{cccccccccc}
\hline Population & T1 & T2 & M2 & M3 & D1 & D2 & D3 & Q1 & Q2 \\
\hline T1 & $\mathbf{0 . 7 5 0}$ & 0.063 & 0.000 & 0.083 & 0.500 & 0.000 & 0.000 & 0.000 & 0.000 \\
T2 & 0.250 & $\mathbf{0 . 6 2 5}$ & 0.333 & 0.000 & 0.000 & 0.000 & 0.000 & 0.000 & 0.000 \\
M2 & 0.000 & 0.125 & $\mathbf{0 . 3 3 3}$ & 0.000 & 0.000 & 0.000 & 0.000 & 0.000 & 0.000 \\
M3 & 0.000 & 0.063 & 0.000 & $\mathbf{0 . 9 1 7}$ & 0.000 & 0.000 & 0.100 & 0.000 & 0.000 \\
D1 & 0.000 & 0.125 & 0.000 & 0.000 & $\mathbf{0 . 0 0 0}$ & 0.000 & 0.100 & 0.000 & 0.000 \\
D2 & 0.000 & 0.000 & 0.000 & 0.000 & 0.000 & $\mathbf{0 . 8 1 8}$ & 0.000 & 0.250 & 0.000 \\
D3 & 0.000 & 0.000 & 0.333 & 0.000 & 0.500 & 0.182 & $\mathbf{0 . 8 0 0}$ & 0.000 & 0.000 \\
Q1 & 0.000 & 0.000 & 0.000 & 0.000 & 0.000 & 0.000 & 0.000 & $\mathbf{0 . 7 5 0}$ & 0.000 \\
Q2 & 0.000 & 0.000 & 0.000 & 0.000 & 0.000 & 0.000 & 0.000 & 0.000 & $\mathbf{1 . 0 0 0}$ \\
\hline
\end{tabular}

Table 4. Proportion of male individuals classified correctly into their original population over 21 truss network morphometric characters using hold-out procedure.

\begin{tabular}{cccccccccc}
\hline Population & T1 & T2 & M2 & M3 & D1 & D2 & D3 & Q1 & Q2 \\
\hline T1 & $\mathbf{0 . 6 2 5}$ & 0.000 & 0.000 & 0.000 & 0.000 & 0.000 & 0.000 & 0.000 & 0.067 \\
T2 & 0.000 & $\mathbf{1 . 0 0 0}$ & 0.000 & 0.000 & 0.000 & 0.000 & 0.000 & 0.000 & 0.000 \\
M2 & 0.000 & 0.000 & $\mathbf{0 . 6 2 5}$ & 0.167 & 0.111 & 0.000 & 0.000 & 0.000 & 0.000 \\
M3 & 0.000 & 0.000 & 0.125 & $\mathbf{0 . 5 0 0}$ & 0.111 & 0.000 & 0.000 & 0.000 & 0.000 \\
D1 & 0.250 & 0.000 & 0.000 & 0.000 & $\mathbf{0 . 6 6 7}$ & 0.000 & 0.000 & 0.000 & 0.000 \\
D2 & 0.000 & 0.000 & 0.125 & 0.000 & 0.000 & $\mathbf{0 . 8 3 3}$ & 0.125 & 0.000 & 0.000 \\
D3 & 0.000 & 0.000 & 0.000 & 0.000 & 0.111 & 0.000 & $\mathbf{0 . 7 5 0}$ & 0.000 & 0.000 \\
Q1 & 0.000 & 0.000 & 0.000 & 0.000 & 0.000 & 0.000 & 0.000 & $\mathbf{0 . 7 5 0}$ & 0.067 \\
Q2 & 0.125 & 0.000 & 0.125 & 0.333 & 0.000 & 0.167 & 0.125 & 0.250 & $\mathbf{0 . 8 6 7}$ \\
\hline
\end{tabular}

Table 5. Pairwise $P_{\mathrm{ST}}$ values of wild populations of $G$. rarus, using all size-corrected morphometric variables. Values below diagonal are based on female samples, while values above diagonal are based on male samples.

\begin{tabular}{cccccccccc}
\hline Population & $\mathrm{T} 1$ & $\mathrm{~T} 2$ & $\mathrm{M} 2$ & $\mathrm{M} 3$ & $\mathrm{D} 1$ & $\mathrm{D} 2$ & $\mathrm{D} 3$ & $\mathrm{Q} 1$ & $\mathrm{Q} 2$ \\
\hline T1 & 0.000 & 0.123 & 0.062 & 0.055 & 0.060 & 0.108 & 0.075 & 0.078 & 0.087 \\
T2 & 0.103 & 0.000 & 0.042 & 0.066 & 0.121 & 0.166 & 0.191 & 0.187 & 0.196 \\
M2 & 0.169 & 0.026 & 0.000 & 0.020 & 0.034 & 0.136 & 0.110 & 0.123 & 0.117 \\
M3 & 0.129 & 0.086 & 0.103 & 0.000 & 0.006 & 0.114 & 0.069 & 0.096 & 0.121 \\
D1 & 0.132 & 0.050 & 0.035 & 0.098 & 0.000 & 0.128 & 0.052 & 0.115 & 0.109 \\
D2 & 0.267 & 0.136 & 0.092 & 0.190 & 0.109 & 0.000 & 0.089 & 0.037 & 0.138 \\
D3 & 0.199 & 0.127 & 0.113 & 0.148 & 0.047 & 0.066 & 0.000 & 0.046 & 0.125 \\
Q1 & 0.223 & 0.140 & 0.107 & 0.163 & 0.105 & 0.049 & 0.057 & 0.000 & 0.139 \\
Q2 & 0.066 & 0.095 & 0.113 & 0.137 & 0.068 & 0.184 & 0.106 & 0.150 & 0.000 \\
\hline
\end{tabular}

Table 6. Correlations $(r)$ and significance $(P)$ between $P_{\mathrm{ST}}, F_{\mathrm{ST}}$ and riparian geographic distance by pairwise and partial Mantel test. When doing partial Mantel test, riparian geographic distance was considered as a controlled factor.

\begin{tabular}{lcccc}
\hline \multirow{2}{*}{ Comparisons } & \multicolumn{2}{c}{ Female samples } & \multicolumn{2}{c}{ Male samples } \\
\cline { 2 - 5 } & $r$ & $P$-value & $r$ & $P$-value \\
\hline Pairwise Mantel test & 0.336 & 0.073 & -0.137 & 0.747 \\
$P_{\mathrm{ST}}-F_{\mathrm{ST}}$ & & & & \\
$P_{\mathrm{ST}}-$ Riparian geographic distance & 0.236 & 0.080 & 0.004 & 0.470 \\
Partial Mantel test & & & & \\
$P_{\mathrm{ST}-F_{\mathrm{ST}}}$ & 0.280 & 0.104 & -0.166 & 0.790 \\
\hline
\end{tabular}

microsatellite loci in female samples $(P>0.05)$. However, significant correlations between $P_{\mathrm{ST}}$ and $F_{\mathrm{ST}}$ were found in two single morphometric traits (D4_6 and D10_9) of female samples, irrespective of whether riparian geographic distance was controlled for (Fig. 6).

A comparison of $F_{\mathrm{ST}}$ and mean $P_{\mathrm{ST}}$ values between population pairs of $G$. rarus revealed that the degree of differentiation in phenotypic traits significantly exceeds that in neutral molecular markers by using Wilcoxon signed-rank tests (Females: $z=-4.666, P<0.001$; Males: $z=-3.079$, $P=0.002)$.

\section{DISCUSSION}

\section{Sexual dimorphism}

The present study revealed sexual dimorphism in G. rarus as approximately $64 \%$ of all the morphometric traits had significant sexual differences. From the distribution of these morphometric variables, it was found that the distances related to landmark 3 (pelvic-fin insertion) of $G$. rarus such as BD (body depth), D2_3, D3_1, D4_3, D3_6 and D5_3 were the most important discriminant factors for sexes. The sexual differences of these morphometric traits were in accordance with the findings in Wang (1992). Wang (1992) found that females usually have a plumper abdomen and a relatively larger body size than males, which is a normal phenomenon in fish (Roff, 1983; Henderson et al., 2003; Kitano et al., 2007). Moreover, Wang (1992) revealed that the distance between the end of pectoral fin rays and the start point of the ventral fin in females of adult G. rarus is approximately one to four scales longer than in males (distance of one to two scales); the distance between the end of ventral fin rays and the cloacal aperture in females is approximately the distance of one to three scales longer than in males (approximately half a scale or sometimes the end of ventral fin rays could reach the cloacal aperture). On the whole, this sexual dimorphism highlights the main differences in the depth of the body shape of $G$. rarus.

Sexual dimorphism in external morphology includes differences in size, coloration, or body structure, which could result from different reproductive roles, niche divergence 
between the sexes, preferences of one sex for particular traits of the other sex, and intra-sexual competition (Andersson, 1994; Kitano et al., 2007; Aguirre et al., 2008). The relatively larger size of females than males is common in G. rarus, which may be explained by several hypotheses including natural selection for greater egg production and sexual selection based on male preference for larger females. Studies have also revealed that sex-determinant mechanisms of $G$. rarus are complicated and may be influenced by environmental factors (You et al., 2010). Therefore, further research on mechanisms responsible for sexual dimorphism of $G$. rarus should be conducted in the future.

\section{Population differentiation}

Although populations were significantly differentiated in females and males according to truss network morphometric traits, we found a certain degree of trait overlap between almost all population pairs. It implied that the degree of population differentiation was not large enough to fully account for their isolation. He et al. (2012) also revealed that a weak but significant geographic isolation between those populations existed within the past few generations, but these may be due to the same historical source. However, it is worth mentioning that population T2 in males (especially) and in females seems to show the highest level of isolation, which could be confirmed by high accuracy of its prediction in males (100\%).

From the distribution of most contribution traits in the body shape of $G$. rarus, it can be found that almost all the truss network traits played important roles in discriminating wild populations. Shao et al. (2007) also revealed that morphological differences between wild populations and inbred strains of $G$. rarus were obviously greater than those among wild populations. These morphological differentiations mainly reflected environmental differences between natural and laboratory conditions. Morphological variation in fish is largely induced by environmental factors, such as rearing temperature, water velocity, food quantity, food type or feeding mode, but not genetic factors (Beacham, 1990; Holopainen et al., 1997; Páez et al., 2008). Through longterm investigation on the habitats of $G$. rarus, the morphological differences between its wild populations are unlikely due to regime or diet, but rather likely due to water velocity.

Our results demonstrate that population differentiation of G. rarus involves not only morphological traits but also neutral genetic markers. He et al. (2012) revealed low to moderate levels of genetic differentiation and a weak but significant isolation-by-distance pattern among these nine wild populations of $G$. rarus, which were highly correlated with the evolution of rivers.

Comparisons between neutral genetic differentiation $\left(F_{\mathrm{ST}}\right)$ and phenotypic variation (phenotypic differentiation in the wild populations should be measured as $P_{\mathrm{ST}}$ ) are increasingly being used in many population studies (Merilä and Crnokrak, 2001; Leinonen et al., 2006; Johansson et al., 2007; Chapuis et al., 2008; Jensen et al., 2008). There are usually three possible interpretations for the comparison: if $P_{\mathrm{ST}}>F_{\mathrm{ST}}$, directional natural selection must be involved to achieve the differentiation; if $P_{\mathrm{ST}}=F_{\mathrm{ST}}$, the observed quantitative differentiation could be obtained by genetic drift alone; if $P_{\mathrm{ST}}<F_{\mathrm{ST}}$, the observed degree of differentiation is actually expected on the basis of selection favoring the same phenotype in different populations (Merilä and Crnokrak, 2001). The majority of studies comparing $P_{\mathrm{ST}}$ and $F_{\text {ST }}$ typically identify diversifying selection as a driver of phenotypic divergence in specific traits of interest (Storz, 2002; Leinonen et al., 2008; Young et al., 2011). In fact, these possible explanations of this comparison rest on many assumptions; for example, it is usually assumed that phenotypic variance equals additive genetic variance, excluding nonadditive genetic and environmental effects (viz., $c=h^{2}$; Merilä, 1997; Brommer, 2011), otherwise they are problematic (Pujol et al., 2008). The critical premise is that local environments differ enough to allow selection acting on additive genetic variation to drive phenotypic divergence of populations. It is likely that different populations experience different environmental conditions, which will create inequality of $c$ and $h^{2}$ (Pujol et al., 2008). The ratio $c / h^{2}$ is the critical aspect that describes how well $P_{\mathrm{ST}}$ approximates $Q_{\mathrm{ST}}$, determining the robustness of the conclusions from the comparison of $P_{\mathrm{ST}}$ with the neutral expectation (Brommer, 2011). Therefore, interpretation of the $P_{\mathrm{ST}}-F_{\mathrm{ST}}$ comparison results in the wild populations should be done with caution.

The present study revealed significant correlations between $P_{\mathrm{ST}}$ over two single traits (D4_6 and D10_9) in female samples and $F_{\mathrm{ST}}$, which could mean that the differentiation of these two traits seems to follow the evolution of a neutral trait only affected by genetic drift. However, there were no significant correlations between $P_{\mathrm{ST}}$ over most traits and $F_{\mathrm{ST}}$, hinting that most of the observed phenotypic discreteness may be not due to genetic drift. Besides, $P_{\mathrm{ST}}$ values clearly exceeded $F_{S T}$ values among wild populations of $G$. rarus. Furthermore, the habitats of $G$. rarus are usually unstable, which is mainly due to environmental changes in the wild (He and Wang, 2010). That is, environmental influences could be the main drivers of phenotypic divergence in G. rarus. In general, many studies have proposed that fish usually demonstrate greater variance in morphological traits and are more susceptible to environmental factors than other vertebrates (Allendorf, 1988; Thompson, 1991; Turan et al., 2006; Langerhans et al., 2007; Young et al., 2011). Environmental influences on traits can arise via two evolutionary processes including natural selection (genetically based responses to selection) as well as phenotypic plasticity (potentially plastic responses to the environment) (Pigliucci, 2001; DeWitt and Scheiner, 2004; Langerhans et al., 2007). Phenotypic plasticity, usually understood as environmentally-induced phenotypic variation, is a major means of adaptation to environmental heterogeneity (Páez et al., 2008; Gianoli and Valladares, 2012). After a change in environment, plasticity can produce a partially adaptive phenotype, which subsequently becomes further adapted by natural selection (Baldwin, 1896; Young et al., 2011). Although our study does not allow the distinction between phenotypic plasticity and natural selection, it is likely that one of these two evolutionary processes (or both) contribute to the observed morphological patterns in G. rarus. More work including experimental studies (i.e., rearing experiments or assessment of local adaptation of coding genes underlying trait variation) would be needed to decipher the relative importance of these processes.

In conclusion, G. rarus shows patterns of morphological 
variation between sexes and among populations. Phenotypic plasticity and natural selection are two evolutionary processes that are likely to contribute to such morphological divergence, the relative importance of which should be investigated with continued research. Knowledge of the patterns of morphological divergence and its driving mechanisms are crucial to the understanding of important evolutionary phenomena and ecological dynamics.

\section{ACKNOWLEDGMENTS}

The authors are grateful to DE Gu for his technical assistance in measurements. We also thank Radika Michniewicz for assisting with English phrasing. This research was supported by funds from the National Natural Science Foundation of China (NSFC, 30670292), the technological fundamental conditions platform program by China Hubei Provincial Science and Technology Department, the Chinese Academy of ScienFces (CZBZX-1), and the Ministry of Environmental Protection of China (2009ZX07527005).

\section{REFERENCES}

Agrawal AA (2001) Phenotypic plasticity in the interactions and evolution of species. Science 294: 321-326

Aguirre WE (2009) Microgeographical diversification of threespine stickleback: body shape-habitat correlations in a small, ecologically diverse Alaskan drainage. Biol J Linn Soc 98: 139-151

Aguirre WE, Ellis KE, Kusenda M, Bell MA (2008) Phenotypic variation and sexual dimorphism in anadromous threespine stickleback: implications for postglacial adaptive radiation. Biol J Linn Soc 95: 465-478

Allendorf FW (1988) Conservation biology of fishes. Conserv Biol 2: 145-148

Andersson M (1994) Sexual Selection. Princeton University Press, Princeton, $\mathrm{NJ}$

Baldwin JM (1896) A new factor in evolution. Am Nat 30: 354-451

Beacham TD (1990) A genetic analysis of meristic and morphometric variation in chum salmon (Oncorhynchus keta) at three different temperatures. Can J Zool 68: 225-229

Bookstein FL, Chernoff B, Elder R, Humphries J, Smith G, Strauss $R$ (1985) Morphometrics in Evolutionary Biology: The Geometry of Size and Shape Change, with Examples from Fishes. Acad Nat Sci Philadelphia Spec Pub 15, Philadelphia, 277 pp

Brommer JE (2011) Whither $P_{\mathrm{ST}}$ ? The approximation of $Q_{\mathrm{ST}}$ by $P_{\mathrm{ST}}$ in evolutionary and conservation biology. J Evol Biol 24: 11601168

Chapuis E, Martin G, Goudet J (2008) Effects of selection and drift on $\mathrm{G}$ matrix evolution in a heterogeneous environment: a multivariate $Q_{\mathrm{ST}}-F_{\mathrm{ST}}$ test with the freshwater snail Galba truncatula. Genetics 180: 2151-2161

Chen YY (1998) Fauna Sinica, Osteichthyes, Cypriniformes II. Science Press, Beijing, China, pp 51-52 (in Chinese)

Clabaut C, Bunje PME, Salzburger W, Meyer A (2007) Geometric morphometric analyses provide evidence for the adaptive character of the Tanganyikan cichlid fish radiations. Evolution 61: 560-578

Collin H, Fumagalli L (2011) Evidence for morphological and adaptive genetic divergence between lake and stream habitats in European minnows (Phoxinus phoxinus, Cyprinidae). Mol Ecol 20: $4490-4502$

Danchin É, Charmantier A, Champagne FA, Mesoudi A, Pujol B, Blanchet $S$ (2011) Beyond DNA: integrating inclusive inheritance into an extended theory of evolution. Nat Rev Genet 12: 475-486

DeWitt TJ, Scheiner SM (2004) Phenotypic Plasticity. Functional and Conceptual Approaches. Oxford University Press, New York
Ding RH (1994) The Fishes of Sichuan, China. Sichuan Publishing House of Science and Technology, Chengdu (in Chinese)

Elmer KR, Fan S, Gunter HM, Jones JC, Boekhoff S, Kuraku S, Meyer A (2010) Rapid evolution and selection inferred from the transcriptomes of sympatric crater lake cichlid fishes. Mol Ecol 19 (Suppl. 1): 197-211

Frankham R, Ballou JD, Briscoe DA (2002) Introduction to Conservation Genetics. Cambridge University Press, New York

Fraser DJ, Bernatchez L (2001) Adaptive evolutionary conservation: towards a unified concept for defining conservation units. Mol Ecol 10: 2741-2752

Gianoli E, Valladares F (2012) Studying phenotypic plasticity: the advantages of a broad approach. Biol J Linn Soc 105: 1-7

Giraudoux P (2006) Pgirmess: data analysis in ecology. R package version 1.3.8. http://perso.orange.fr/giraudoux/

Google Inc. (2009) Google Earth 5.0. http://www.google.com/earth/ index.html

He YF, Wang JW (2010) Temporal variation in genetic structure of the Chinese rare minnow (Gobiocypris rarus) in its type locality revealed by microsatellite markers. Biochem Genet 48: 312325

He YF, Wang JW, Blanchet S, Lek S (2012) Genetic structure of an endangered endemic fish (Gobiocypris rarus) in the upper Yangtze River. Biochem Syst Ecol 43: 214-225

Henderson BA, Collins N, Morgan GE, Vaillancourt A (2003) Sexual size dimorphism of walleye (Stizostedion vitreum vitreum). Can J Fish Aquat Sci 60: 1345-1352

Holopainen IJ, Aho J, Vornanen M, Huuskonen H (1997) Phenotypic plasticity and predator effects on morphology and physiology of crucian carp in nature and in the laboratory. J Fish Biol 50: 781798

Ihaka R, Gentleman R (1996) R: a language for data analysis and graphics. J Comput Graph Stat 299-314

Ihssen PE, Booke HE, Casselman JM, McGlade JM, Payne NR, Utter FM (1981) Stock identification: materials and methods. Can J Fish Aquat Sci 38: 1838-1855

Jensen LF, Hansen MM, Pertoldi C, Holdensgaard G, Mensberg KLD, Loeschcke V (2008) Local adaptation in brown trout early life-history traits: implications for climate change adaptability. Proc R Soc London Ser B doi:10.1098/rspb.2008.0870

Jia FJ, Wang JW, Wu QJ (2002) Gynogenetic rare minnow (Gobiocypris rarus) induced by heterogeneous sperms. Acta Hydrobiol Sin 26: 246-252 (in Chinese)

Johansson M, Primmer CR, Merilä J (2007) Does habitat fragmentation reduce fitness and adaptability? A case study of the common frog (Rana temporaria). Mol Ecol 16: 2693-2700

Kawecki TJ, Holt RD (2002) Evolutionary consequences of asymmetric dispersal rates. Am Nat 160: 333-347

Kitano J, Mori S, Peichel CL (2007) Sexual dimorphism in the external morphology of the threespine stickleback (Gasterosteus aculeatus). Copeia 2: 336-349

Kristjánsson BK, Malmquist $\mathrm{HJ}$, Ingimarsson $\mathrm{F}$, Antonsson $\mathrm{T}$, Snorrason SS, Skúlason S (2011) Relationships between lake ecology and morphological characters in Icelandic Arctic charr, Salvelinus alpinus. Biol J Linn Soc 103: 761-771

Langerhans RB, Layman CA, Langerhans AK, Dewitt TJ (2003) Habitat-associated morphological divergence in two Neotropical fish species. Biol J Linn Soc 80: 689-698

Langerhans RB, Chapman LJ, Dewitt TJ (2007) Complex phenotype-environment associations revealed in an East African cyprinid. J Evol Biol 20: 1171-1181

Leinonen T, Cano JM, Mäkinen H, Merilä J (2006) Contrasting patterns of body shape and neutral genetic divergence in marine and lake populations of threespine sticklebacks. J Evol Biol 19: 1803-1812

Leinonen T, O'Hara RB, Cano JM, Merilä J (2008) Comparative studies of quantitative trait and neutral marker divergence: a 
meta-analysis. J Evol Biol 21: 1-17

Le PQ, Chen YY (1998) China Red Data Book of Endangered Animals: Pisces. Science Press, Beijing, pp 170-172 (in Chinese)

Li L, Ma TW, Wu ZB (2004) Toxic effect of domestic sewage on rare minnow (Gobiocypris rarus). Acta Hydrobiol Sin 28: 40-44 (in Chinese)

Lowe-McConnell RH (1987) Ecological Studies in Tropical Fish Communities. Cambridge University Press, London

Mantel N (1967) The detection of disease clustering and a generalized regression approach. Cancer Res 27: 209-220

Merilä J (1997) Quantitative trait and allozyme divergence in the Greenfinch (Carduelis chloris, Aves: Fringillidae). Biol J Linn Soc 61: 243-266

Merilä J, Crnokrak P (2001) Comparison of genetic differentiation at marker loci and quantitative traits. J Evol Biol 14: 892-903

Morrissey MB, de Kerckhove DT (2009) The maintenance of genetic variation due to asymmetric gene flow in dendritic metapopulations. Am Nat 174: 875-889

Murta AG (2000) Morphological variation of horse mackerel (Trachurus trachurus) in the Iberian and North Africa Atlantic: implications for stock identification. ICES J Mar Sci 57: 12401248

Oliveira RF, Almada VC (1995) Sexual dimorphism and allometry of external morphology in Oreochromis mossambicus. J Fish Biol 46: 1055-1064

Páez DJ, Hedger R, Bernatchez L, Dodson JJ (2008) The morphological plastic response to water current velocity varies with age and sexual state in juvenile Atlantic salmon, Salmo salar. Freshwater Biol 53: 1544-1554

Pei DS, Sun YH, Zhu ZY (2008) Construction of cytoplasmic molecular markers distinguishing Danio rerio from Gobiocypris rarus at high identity domains based on MP-PCR strategy and Sybr Green I detection. Mol Biol Rep 35: 45-50

Pigliucci M (2001) Phenotypic Plasticity. Beyond Nature and Nature. Johns Hopkins University Press, Baltimore, MD

Pigliucci M (2005) Evolution of phenotypic plasticity: where are we going now? Trends Ecol Evol 20: 481-486

Pujol B, Wilson J, Ross RIC, Pannell JR (2008) Are Qst-Fst comparisons for natural populations meaningful? Mol Ecol 17: 4782-4785

Raeymaekers JAM, Van Houdt JKJ, Larmuseau MHD, Geldof S, Volckaert FAM (2007) Divergent selection as revealed by $P_{\mathrm{ST}}$ and QTL-based $F_{\mathrm{ST}}$ in three-spined stickleback (Gasterosteus aculeatus) populations along a coastal-inland gradient. Mol Ecol 16: 891-905

Reist JD (1985) An empirical evaluation of several univariate methods that adjust for size variation in morphometric data. Can $\mathrm{J}$ Zool 63: 1429-1439

Roff DA (1983) An allocation model of growth and reproduction in fish. Can J Fish Aquat Sci 40: 1395-1404

Roff DA (1992) The Evolution of Life Histories: Theory and Analysis. Chapman and Hall, New York

Rohlf FJ (2005) tpsDig, digitize landmarks and outlines, version 2.04. Department of Ecology and Evolution, State Univesity of New York at Stony Brook

Shao Y, Wang JW, Qiao Y, He YF, Cao WX (2007) Morphological variability between wild populations and inbred stocks of a Chinese Minnow, Gobiocypris rarus. Zool Sci 24: 1094-1102

Shapiro SS, Wilk MB (1965) An analysis of variance test for normality (complete samples). Biometrika 52: 3-4, 591

Silva A (2003) Morphometric variation among sardine (Sardina pilchardus) populations from the northeastern Atlantic and the western Mediterranean. ICES J Mar Sci 60: 1352-1360

Skjæraasen JE, Rowe S, Hutchings JA (2006) Sexual dimorphism in pelvic fin length of Atlantic cod. Can J Zool 84: 865-870

Snedecor GW, Cochran WG (1989) Statistical Methods ( $8^{\text {th }}$ edition). lowa State University Press, Ames, lowa

Sokal RR, Rohlf FJ (1995) Biometry. W. H. Freeman, New York

Spitze K (1993) Population structure in Daphhnia obtusa: quantitative genetic and allozymic variation. Genetics 135: 367-374

StatSoft Inc (2001) STATISTICA (data analysis software system), version 6. www.statsoft.com

Stelkens RB, Jaffuel G, Escher M, Wedekind C (2012) Genetic and phenotypic population divergence on a microgeographic scale in brown trout. Mol Ecol 21: 2896-2915

Storz JF (2002) Contrasting patterns of divergence in quantitative traits and neutral DNA markers: analysis of clinal variation. Mol Ecol 11: 2537-2551

Strauss RE, Bookstein FL (1982) The truss: body form reconstructions in morphometrics. Syst Zool 113-135

Su JG, Zhu ZY, Wang YP (2008) Molecular cloning, characterization and expression analysis of the PKZ gene in rare minnow Gobiocypris rarus. Fish Shellfish Immunol 25(1-2): 106-113

Thompson JD (1991) Phenotypic plasticity as a component of evolutionary change. Trends Ecol Evol 6: 246-249

Turan C, Oral M, Öztürk B, Düzgünes E (2006) Morphometric and meristic variation between stocks of Bluefish (Pomatomus saltatrix) in the Black, Marmara, Aegean and northeastern Mediterranean Seas. Fish Res 79: 139-147

Wang JW (1992) Reproductive biology of Gobiocypris rarus. Acta Hydrobiol Sin 16: 165-174 (in Chinese)

Wang JW (1996) Studies on critical temperature of Gobiocypris rarus. Sichuan J Zool 15: 153-155 (in Chinese)

Wang JW (1999) Spawning performance and development of oocytes in Gobiocypris rarus. Acta Hydrobiol Sin 23: 161-166 (in Chinese)

Wang JW, Cao WX (1997) Gobiocypris rarus and fishes as laboratory animals. Trans Chinese Ichthyol Soc 6: 144-152 (in Chinese)

Wang S, Xie Y (2004) China Species Red List, vol. 1. Red List. Higher Education Press, Beijing, p 158-159 (in Chinese)

Wang TH, Liu PL, Chen HX, Liu HQ, Yi YL, Guo W (1994) Preliminary study on the susceptibility of Gobiocypris rarus to Hemorrhagic Virus of Grass Carp (GCHV). Acta Hydrobiol Sin 18: 144-149 (in Chinese)

Wang ZH, Yin YW, Xu ZN, Zhou J, Zhang Q, Zhang DP (1998) Acute and subchronic toxicity of pyrethroid insecticides to Gobiocypris rarus. Chinese J Appl Environ Biol 4: 379-382 (in Chinese)

Williams TM, Carroll SB (2009) Genetic and molecular insights into the development and evolution of sexual dimorphism. Nat Rev Genet 10: 797-804

Wright S (1951) The genetical structure of populations. Ann Eugen 15: 323-354

Xiong DM, Xie CX, Xia L (2009) Threatened fishes of the world: Gobiocypris rarus Ye and Fu, 1983 (Cyprinidae). Environ Biol Fish 86: 107-108

Ye MR, Fu TY (1983) Description of a new genus and species of Danioninae from China (Cypriniformes: Cyprinidae). Acta Zootaxon Sin 8: 434-437 (in Chinese)

You CH, Tong JG, Wang JW, Yu XM, Li YY (2010) Preliminary study on the sex determination in rare minnow (Gobiocypris rarus). Acta Hydrobiol Sin 34: 225-228 (in Chinese)

Young MJ, Evans JP, Simmons LW (2011) Population genetic structure and a possible role for selection in driving phenotypic divergence in a rainbowfish (Melanotaeniidae). Biol J Linn Soc 102 $144-160$

Zhong XP, Xu Y, Liang Y, Liao T, Wang JW (2005) The Chinese rare minnow (Gobiocypris rarus) as an in vivo model for endocrine disruption in freshwater teleosts: a full life-cycle test with diethylstilbestrol. Aquat Toxicol 71: 85-95

(Received March 21, 2012 / Accepted December 28, 2012) 